\title{
Absent radius-anogenital anomalies syndrome
}

INSERM

\section{Source}

INSERM. (1999). Orphanet: an online rare disease and orphan drug data base. Absent radius-anogenital anomalies syndrome. ORPHA:3016

Absent radius-anog enital anomalies syndrome is a rare, genetic limb reduction defects syndrome characterized by bilateral radial aplasia/hypoplasia manifesting with absent/short forearms in association with anogenital abnormalities (e.g. hypospadias or imperforate anus). Additional features reported include hydrocephalus and absent preaxial digits. There have been no further descriptions in the literature since 1993. 